\title{
CORPORATE LOCATION POLICY IN THE AGE OF GLOBALIZATION
}

\author{
Andreas Palm \\ Am Deutschherrenberg 30, 35578 Wetzlaz, Divisburg, Germany \\ E-mail: andreas.palm@web.de \\ Received 1802 2005; accepted 27032005
}

\begin{abstract}
In today's economy it is very important how companies select locations for headquarters, production sites and sales offices. This paper places particular emphasis on the effects on corporate location policy resulting from a constantly proceeding globalization. Therefore the term globalization is defined first. Then, using a globally present company as an example the process of deciding on locations is illustrated. Finally, there is an outlook on future demands globalization will place on corporate location policy.
\end{abstract}

Keywords: globalization, corporate location policy, location selection, and global competition.

\section{Introduction}

Nowadays, globalization has become such a relevant, commonly used term that a close examination of its meaning seems very important. This article places particular emphasis on the effects and demands of corporate location policy, which result from a constantly proceeding globalization [1-3].

The globally operating company Leica Microsystems serves as a vivid example for the issue at hand. With the aid of this example, the globalization and location policy concepts, and the practical relevance of these terms, will become significantly clearer.

Part one will clarify the term globalization, which is often associated with negative topics in the media, such as unemployment in industrial countries.

An overview of Leica Microsystems is then presented, followed by an examination of corporate location policy in general, and Leica Microsystems' approach in particular. Apart from corporate information material available from the firm's online platform, this examination was primarily based on insights gained through discussions with the company's Executive Board.

Finally, an attempt will be made to offer an outlook on future demands globalization will place on corporate location policy, as well as policy-makers responsible for decisions on locations.

\section{What Does Globalization Mean?}

Both of the following definitions of globalization seem particularly plausible:

- Globalization describes the gradual integration of markets, cultures, and political fields on a global scale with pre-viously unknown intensity.

- Globalization is the global networking of economic activities with effects on society, economy, politics, and culture. Apart from the traditional form of foreign commerce, foreign investments and manufacturing are also included here, as well as cooperation with foreign corporations or other institutions [2]. 
Globalization has many facets; it is simultaneously a process and a state. At the same time, causes and effects cannot always be precisely differentiated due to the complexity of the phenomenon. Some such causes and implications include:

- Social/Political: liberalization of markets, democratization, growing formation of provision of services

- Economic: saturated markets for industrial products, growing relevance of service, manufacturers follow consumers, strategic alliances emerge

- Technological: new information and communication technologies, new possibilities in traffic engineering [2].

Historically seen, globalization developed from a steady rise in the complexity of economic processes. From the 15th century on, there was a sales-based internationalization. In the late 19 th century, multinationalization was established with the purpose of purveying to and manufacturing in other markets. Around 1980, globalization began with a systematic presence in all markets and areas of business including Research \& Development (R\&D) and specific alliances and co-operations with competitors.

Amongst the winners of globalization are industrial nations with access to new technologies and knowledge - but certainly not all people in these countries - as well as some classes in developing countries, e.g. the "computer scientist caste" in India.

Globalization underdogs are the so-called "computer illiterates", who have no access to the new technologies, as well as underdeveloped countries, who face a growing technological gap between them and the developed industrial nations.

One definite, obvious consequence of globalization is the ensuing comparison of systems and models, e.g. administrative benchmarking. Moreover, globalization could lead to a loss of sovereignty of nations, or to a 20:80 society in which only 20 percent of the population perform relevant, well-paid work, and the remainder of the population is more or less pacified. [4].

With this definition of globalization the location policy of globally operating companies will be researched.

\section{Corporate Location Policy}

\subsection{Overview of Leica Microsystems}

Leica Microsystems describes itself as a leading global innovator, manufacturer and supplier of high precision optical solutions that are based on microscopes and related instruments. The corporate headquarters are located in Wetzlar, in the German state of Hesse.

The company manufactures a wide-ranging portfolio of products used in a broad variety of applications which require vision, measurement, analysis or lithography. This includes applications in the life sciences, e.g. bio-technology research and medicine, the material sciences, industrial inspection as well as the semiconductor manufacturing industry. With over 3600 employees and customers in over 100 countries the generated annual sales revenues in the fiscal year to 2003 were 521 million Euros.

Leica Microsystems operates through two divisions, each supported by its own international sales and service teams. The Microsystems division includes the business segments of microscopy, imaging systems, specimen preparation and medical equipment. The Semiconductor Equipment division includes strategic business units supplying standalone inspection microscopes, inspection, review and defect detection and classification stations, mask metrology equipment and electron beam lithography tools for the manufacture of microchip devices.

The company has a global presence comprising 10 manufacturing facilities in North America, Europe and Asia/Pacific as well as a sales, distribution and service network of completely owned subsidiaries and branches that is present in 19 countries and a complementary network of more than 200 dealers around the world. Part of the company's values is that it provides its products and services worldwide, through local organizations communicating in local languages. All business units have an international, multicultural mix of staff [5].

\subsection{The Question of Location from the Corporate Perspective}

The decision-making authority of managers to establish new manufacturing or development divisions (or to relocate existing divisions) where the overall mix of location factors seems the most economically advantageous for the operating corporation was never as great as it was today. Individual assessment criteria are characterized as location factors, through the help of which manufacturing and servicing corporations can attempt a systematical selection of the optimal location for the development of a new (or the relocation of an existing) corporate division [6].

What is actually considered an "optimal" location ultimately depends on the individual corporate goals. 
Generally speaking however, for acquisitive companies, it can be said that a location is all the more positive, the larger the difference is between locationdependent revenue and location-contingent expenditures.

Even in today's age of increased mobility, the choice of a corporate location is, together with the decision on a company's legal structure, the management decision that has to be most based on long-term considerations. Because of its consequences, this decision should be carefully planned and systematically implemented. Decision criteria can be divided into six major subsections for systemization:

- material orientation,

- work orientation,

- tax and subsidy orientation,

- energy orientation,

- infrastructure orientation,

- and profit orientation [7].

In the case of material orientation, deciding on a location is primarily based on the lowest possible costs of material procurement for manufacturing. However, not only material costs have to be considered here, but also the quality and the available quantity.

Work oriented corporations favor regions with potentially low wages for the required level of qualification.

Stateside subsidies and expenditures, which can be directly influenced in a particular location, are the focus of tax and subsidy orientation. International "tax havens" are attractive, as well as those regions with high state subsidies.

Energy orientation gains importance for companies with a high level of power consumption. Attention is paid here to an ample power supply and the lowest possible energy prices.

With regard to the infrastructure orientation, preferred locations include those with traffic hubs and areas with a generally good transport connection, as well as regions with fully developed telecommunication networks. In addition, the state of the education system, i.e. the education level of skilled workers, the quality and the number of available university graduates and existing research institutes all play a role in the infrastructure.

From the profit orientation perspective, customer location also plays a relevant role. The company therefore primarily seeks a close connection to its customer, or also access to a well funded regional or national market [7].

Such a range of location factors cannot be expressed a priori in monetary units. Due to financial efficacy, differentiation is therefore made between financial and non-financial location factors in business economics.

Among the financial location factors are, for example, real estate prices or expenditures for the raw materials necessary for production. Yet costs for factors that are actually difficult to assess, such as climatic conditions, can also be expressed in monetary values. For example, if a particular climate makes air conditioning or a special transporter necessary, expenditures for the climatic factor can be roughly approximated. A comparison of individual location alternatives can be made with the aid of a cost effectiveness analysis.

Political stability, location image or recreational value of the region are all non-financial location factors. A ranking order here can only be made based on specific preferences of individual companies and more or less subjective estimations [1,7].

\section{3 Choice of Location at Leica Microsystems}

As a supplement to the previous section, this section discusses the question of how the company specifically conducts its location policy, with special emphasis on how the selection of a location is made.

Before a decision is made on the selection of a new location, the company first compiles some of its own studies of potential locations. These studies chiefly focus on a cost calculation, but the efficiency and quality structure of the respective locations are also taken into consideration. All of this can be expressed with the aid of formulas, which are especially adapted to the respective area of business operations.

Nonetheless, there are also factors that influence the quality of a location, which are very difficult or even impossible to express in numbers. Two examples are social peace or the political stability of a region.

Many different factors play a role in the selection of a location. The emphasis of individual factors strongly depends on what purpose the new location is to be used for in the future. As an example, low wages in an Asian location will not influence the decision if automated manufacturing is foreseen for that location, and a higher product quality can be attained in a different location, albeit for higher labor costs.

Of course, apart from the location selection, of particular importance for the company are all elements that directly or indirectly influence the overall expenditures. Nevertheless, great value is placed on being able to work or manufacture upholding the Leica Microsystems quality standards. 


\section{Summary and Perspective}

In conclusion, after having introduced Leica Microsystems and its assessment of various location factors, attention shall be shifted to the current situation in the economic-political debate on the assessment of globalization and its effects on national locations.

Through progressive globalization and the upsurge of new countries in a more liberal climate of world trade, the German economy for example has been facing ever-stronger competition since the early 1980's. Whereas the effects of this competition were able to remain rather latent due to the fall of the German Democratic Republic and German reunification in 1990 and other factors, by the mid-nineties at the latest, the ramifications of competition had grown obvious. As a result criticism of Germany as a business location has since grown loud [8].

The amount of direct foreign investments made in a certain location, i.e. in the respective state, is regarded as a key figure for the attractiveness of a location. However, this criterion has to be viewed with caution. A large proportion of foreign corporate engagement cannot even be grasped with the help of this criterion, as the necessary assets from banks and other financial institutions are provided within the respective state and, thus, are not registered as cash flow between states. For this reason, overall invest-ments in one state should also be taken into consideration when assessing the attractiveness of a location. Funding by foreign investors also alludes to the assessment of a location's qualities [9].

Since the mid-eighties, European and Japanese markets have steadily lost their relevance for world trade. Although a large percentage of international trade still takes place between OECD nations, markets of the newly industrializing nations (in South-east Asia, South Asia and Eastern Europe) exhibit significantly larger growth rates [3].

With prosperity on the rise in these emerging regions, development of the infrastructure and, in particular, the development of a strong scientific infrastructure, has been improved. In such, the companies in these regions now not only have access to an army of workers earning extremely low wages for the production of cheap mass products, but also to qualified workers for high-quality products. In this context, they compete with established locations for the development of manufacturing and R\&D facilities $[3,9]$.

The fast-paced advancements in the information and communication technologies (satellite broadcasting,
Internet and intranet, ISDN, computers) have made worldwide data exchange and synchronization possible. Through this, the prerequisites were created with which a far-away market can be observed and evaluated, thus motivating activity in this market.

Through the rise of global trade and the advancements made in the information and communication technology, the worldwide technological transfer has greatly expanded. Technological progress - partially implemented by the corporations themselves in order to deliberately curtail product lifecycles - is spurned on even faster by companies, making it a downright contest of innovation. The advantage that a location attains through this - it gains a head start through the exclusive use of new and more efficient manufacturing or organization technologies - can, however, only be maintained for a short period of time.

Due to increased trade with multiple countries with free exchange rates, the risk of losses due to exchange rate fluctuations has grown for individual corporations. Hedging foreign trade therefore equates to an increase in expenditures for the company. Another strategy is the dispersion of production plants throughout different countries/monetary areas, in order to balance out exchange rate fluctuations.

The generally increased mobility of capital, knowledge, and higher qualified workers intensifies the above-mentioned effects in conjunction with decreased transport costs.

Simple export and import of goods and services in these markets is not enough to partake of the growth of other markets. On one hand, there are still too many trade barriers for a massive export to these countries, and on the other hand, a certain degree of customer proximity is needed for many higher quality products in order to react more quickly and precisely to customer wishes and thereby attain a decisive competitive edge. Moreover, through the targeted dispersion of their locations, corporations try to make use of comparative cost advantages in their own value creation chain.

In closing, it can be said that the globalization phenomenon offers more chances than risks. Instead of damning globalization and painting a bleary picture, job markets should be liberalized and education should be facilitated. Complaints of hardships and risks that the change will bring about are understandable. The global trend towards worldwide unity is, however, irreversible. "Working men of all countries, unite!" was what The Communist Manifesto propagated. In this sense, the new parole for the age of globalization should be: "Workers of the world, face the competition!" [10]. 


\section{References}

1. Bea, Franz Xaver, Erwin Dichtl, Marcell Schweitzer (Ed.): Allgemeine Betriebswirtschaftslehre, Bd. 1, 6. Auflage, Stuttgart und Jena, 1992.

2. Bundesverband der deutschen Industrie e.V. (Ed.): Benchmarking im internationalen Standort-Wettbewerb, Köln, 1997.

3. OECD: La Mondilasation de L,Inustrie, Vue d,ensemble et rapports sectoriels; Paris, 1996.

4. Paque, Karl-Heinz: Weltwirtschaftlicher Strukturwandel und die Folgen, in: Aus Politik und Zeitgeschichte, B 49/95, Bonn, 1995.
5. http://www.leica-microsystems.com/website/lms.nsf, 4.1.2005.

6. Rauscheder, Winfried: Stichwort Wirtschaftsstandort Deutschland, München, 1994.

7. Schierenbeck, Henner: Grundzüge der Betriebswirtschaftslehre, 12. Auflage, München, 1995.

8. Die Welt, 09.07.1997, p.14.

9. Wortmann, Michael: Direktinvestitionen, Arbeitsplatzexporte und die Wettbewerbsfähigkeit des Standortes Deutschland, Bonn 1997.

10. Die Welt, 13.05.1997, p. 14. 